\title{
Validity and reliability of the Persian (Farsi) version of the Job Content Questionnaire: a study among hospital nurses
}

A. Choobineh, ${ }^{1}$ H. Ghaem ${ }^{2}$ and P. Ahmedinejad ${ }^{3}$

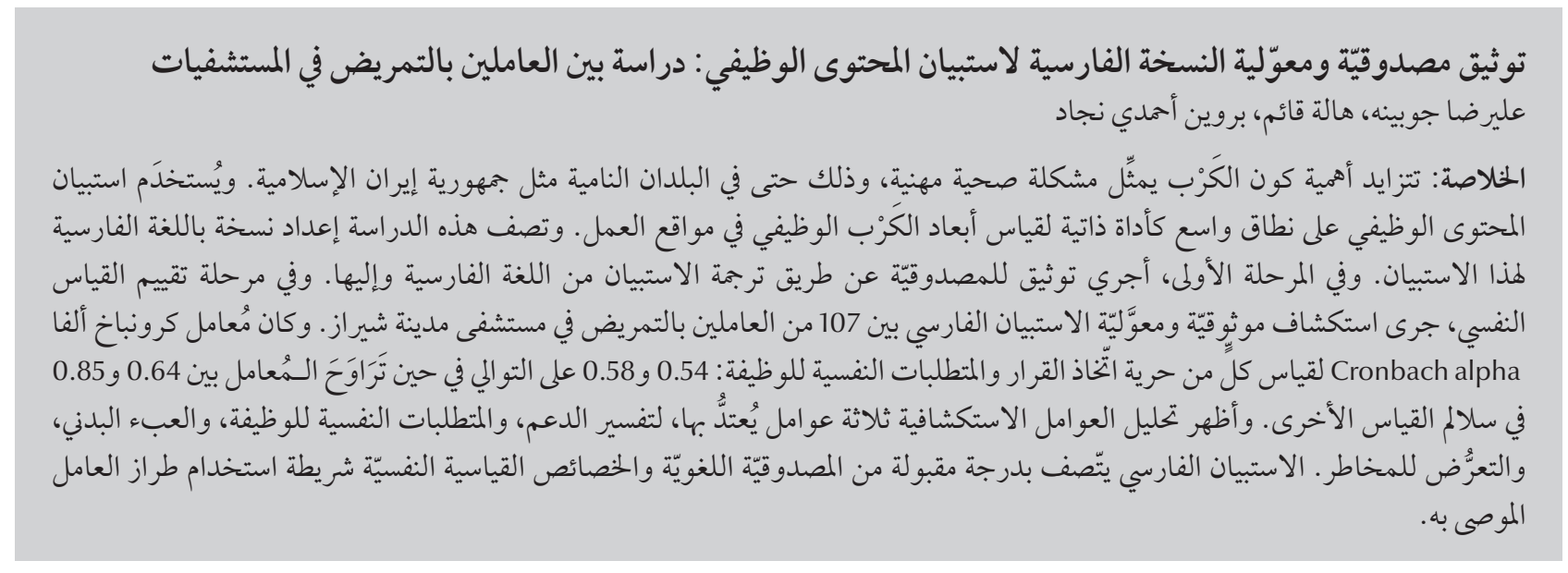

ABSTRACT Stress is an increasingly important occupational health problem, even in developing countries such as the Islamic Republic of Iran. The Job Content Questionnaire (JCQ) is a widely used self-administered instrument to measure dimensions of job stress in the workplace. This study describes the preparation of a Persian (Farsi) language version of the questionnaire (P-JCQ). In the first stage, linguistic validation was done by forward and backward translation. In the psychometric evaluation stage, the reliability and validity of the P-JCQ were explored among 107 hospital nurses in Shiraz city. Cronbach alpha coefficients for decision latitude and psychological job demands scales were 0.54 and 0.58 respectively and ranged from 0.64 to 0.85 for other scales. Exploratory factor analysis showed 3 meaningful factors that could explain support, psychological job demands and physical loads and hazard exposure. The P-JCQ has satisfactory linguistic validity and psychometric properties, provided the recommended factor pattern is used.

Validité et fiabilité de la version en langue perse (farsi) du Questionnaire de Karasek : une étude chez le personnel infirmier en milieu hospitalier

RÉSUMÉ Le stress représente un problème de santé au travail de plus en plus important, même dans les pays en développement comme la République islamique d'Iran. Le Questionnaire de Karasek, en anglais Job Content Questionnaire (JCQ), est un auto-questionnaire très utilisé pour mesurer les dimensions du stress professionnel. La présente étude décrit la préparation de la version en langue perse (farsi) du questionnaire (P-JCQ). Lors de la première étape, une validation linguistique a été conduite aux moyens d'une traduction vers la langue cible puis d'une rétro-traduction vers la langue source. À l'étape de l'évaluation psychométrique, la fiabilité et la validité du questionnaire P-JCQ ont été explorées auprès de 107 membres du personnel infirmier de la ville de Chiraz. Les coefficients alpha de Cronbach pour les échelles concernant la latitude décisionnelle et les demandes psychologiques au travail étaient de 0,54 et 0,58, respectivement, et allaient de 0,64 à 0,85 pour les autres échelles. Une analyse de facteur exploratoire a révélé trois facteurs significatifs capables d'expliquer les résultats concernant le soutien, les demandes psychologiques, les charges physiques et l'exposition au danger au travail. Le questionnaire P-JCQ possède une validité linguistique et des propriétés psychométriques satisfaisantes, dans la mesure où la structure factorielle recommandée est utilisée. 


\section{Introduction}

Stress has become an increasingly important occupational health problem and a significant cause of economic loss throughout the world [1]. A number of studies with a cross-sectional or prospective design have shown a variety of adverse health outcomes to be positively associated with job stress [1-8].

The Job Content Questionnaire (JCQ) is a widely used self-administered instrument to measure the social and psychological structure of the work situation [9]. The well knowndemandscontrol-support model of job strain, as proposed by Karasek, predicts that job strain will occur when the psychological job demands are high and the worker's decision latitude is low, and that low support would increase the risk $[1,9]$. The core scales of the JCQ therefore consist of 3 elements: decision latitude, psychological job demands and social support. Two other aspects of work demands are also assessed: physical job demands and job insecurity. The instrument has a recommended length of 49 questions [9]. Based on the conditions and aims of any given study, other questions may be included to measure other aspects of the job. For instance, to control for physical hazards at work, the 9-item physical hazard and exposure scale is recommended. These result in a 58-item questionnaire which can be used to analyse job characteristics and assess the relative risks of individual exposure to different work settings and thus to predict job-related illness such as psychological distress, coronary heart diseases, musculoskeletal disorders and reproductive disorders [9]. The JCQ has been translated into over a dozen languages. An international board of research, the JCQ Center based at the University of Massachusetts, United States of America, is responsible for the development of the questionnaire [9].

As the JCQ has been developed and applied mostly in industrialized countries, its usability is yet to be tested in different cultures where traditional societies are being affected by rapid technological changes [10]. With increasing industrialization in the Islamic Republic of Iran job stress is becoming a risk factor for the health and safety of the workforce. Preparation of a Persian (Farsi) language version of the questionnaire is therefore an important step to enable systematic studies on job stress that can inform occupational health interventions among Iranian workers. The aims of the present study were: to develop a Persian version of the JCQ (P-JCQ) and make it available to the Iranian scientific community; and to investigate the psychometric properties of selected scales of the P-JCQ on a sample of nurses employed in Shiraz city hospitals.

\section{Methods}

\section{The questionnaire}

As the questionnaire was intended to be used in the occupational health context, 39 relevant items, covering the core set of items, were selected from the full version of the JCQ [11]. They were as follows: decision latitude (9 items); psychological job demands (9 items); social support (8 items); physical exertion (3 items); and physical isometric loads ( 2 items). Questions about physical hazard and exposure ( 8 items), as recommended by Karasek [11], were added to the questionnaire to control for physical hazards at work that may contribute to the outcomes.

Each of the questions had a 4-point response ranging from 1 (strongly disagree) to 4 (strongly agree). In some cases, less than 4 responses (i.e. physical hazards and exposure questions) or more than 4 responses (i.e. social support questions) were provided. The scale calculations were performed in accordance to the JCQ user's guide [11].

In addition to items from the P-JCQ, the self-administrated questionnaire also contained questions on demographic characteristics, i.e. race, sex, age, education, marital status, work history and medical status.

\section{Linguistic validation}

The first step was translation to ensure the linguistic validity of the questionnaire in the new language. The 39-item JCQ was translated into Persian by a qualified translator, who was a native speaker of Persian and proficient in English (forward translation), and then translated back into English by a qualified English translator, blind to the original English questions (backward translation). The JCQ Center reviewed the back-translated English version for comparison with the original version. Based on the reviews, some items were corrected.

To check the understanding and interpretation of the translated items among a group of the Iranian workforce and thereby validate the conceptual equivalence between the English and the Persian version (cognitive debriefing), the P-JCQ was administered to 20 hospital nurses. The nurses were asked to put a note beside any ambiguous questions. Based on the JCQ Center amendments and the nurses' notes, the final P-JCQ was prepared.

The process of linguistic validation of the P-JCQ has been presented in detail elsewhere [12].

\section{Psychometric evaluation}

The second step was to evaluate the psychometric properties of the questionnaire. In this stage of the study conducted from March to July 2008, the 39-item P-JCQ was administered anonymously to 107 randomly selected nurses employed in 6 university hospitals located in Shiraz city, in the south of the Islamic Republic of Iran.

The study protocol was reviewed and approved by Shiraz University of Medical Sciences ethics committee and the study was conducted in accordance with the revised Helsinki Declaration of 1989. All of the participants signed 
an informed consent form before the study began. A cover note guaranteed the subjects' confidentiality. She/he was informed of the aims, methods and anticipated benefits of the study and that she/he was at liberty to abstain from participation in the study and that she/he was free to withdraw her or his consent to participation at any time. Each subject received the questionnaire in person in her/his workplace. Each subject was given 30 minutes to complete the questionnaire and return it to the researcher.

The internal consistency of the scores on the scales was assessed using Cronbach alpha coefficients (recommended value $a \geq 0.70$ ) [13]. Spearman correlation coefficient was used to assess assessing convergent validity between items within scales and between-scale correlations as well as scaling success. Construct validity was assessed through factor analysis.

All analyses were conducted using SPSS, version 13.

\section{Results}

\section{Demographic characteristics}

The demographic characteristics of the subjects are presented in Table 1. Of the 107 nurses in this study, $89.7 \%$ were female. The mean (standard deviation) age and job tenure of the participants were 32.3 (SD 7.3) and 9.9 (SD 6.7) years respectively. Among the subjects, $41.0 \%$ were single, $53.3 \%$ were married and $1.9 \%$ and $3.8 \%$ were divorced and widowed respectively. Of the nurses 91\% had a BSc degree and the remainder had an MSc or PhD. Of all subjects, $19.8 \%$ were day workers and the others worked a shift system.

\section{P-JCQ scores}

The mean scores for each P-JCQ scale gained by the study nurses are shown in Table 2. The minimum and the maximum scores that a subject could gain in each scale are also presented for comparison.

\section{Internal consistency reliability}

As shown in Table 3, the Cronbach alpha coefficients for the social support scale (0.85), physical exertion scale (0.64), physical isometric loads scale (0.81) and total physical hazards (0.85) were $\geq 0.64$, indicating acceptable internal consistency, whereas the coefficient for decision latitude and psychological job demands scales were only 0.54 and 0.58 respectively.

\section{Convergent validity}

Table 4 shows the Spearman correlations for assessing convergent validity:

\begin{tabular}{|c|c|}
\hline \multicolumn{2}{|c|}{$\begin{array}{l}\text { Table } 1 \text { Demographic characteristics of } \\
\text { the study nurses }(n=107)\end{array}$} \\
\hline Characteristic & Value \\
\hline \multicolumn{2}{|l|}{$\operatorname{Sex}(\%)$} \\
\hline Female & 89.7 \\
\hline Male & 10.3 \\
\hline \multicolumn{2}{|l|}{ Age (years) } \\
\hline Mean (SD) & $32.3(7.3)$ \\
\hline Min-max & $22-52$ \\
\hline \multicolumn{2}{|l|}{ Job tenure (years) } \\
\hline Mean (SD) & $9.9(6.7)$ \\
\hline Min-max & $2-28$ \\
\hline \multicolumn{2}{|l|}{ Marital status (\%) } \\
\hline Single & 41.0 \\
\hline Married & 53.3 \\
\hline Divorced & 1.9 \\
\hline Widowed & 3.8 \\
\hline \multicolumn{2}{|l|}{ Education (\%) } \\
\hline BSc degree & 91.0 \\
\hline MSc or PhD degree & 9.0 \\
\hline \multicolumn{2}{|l|}{ Shift schedule (\%) } \\
\hline Day (fixed) & 19.8 \\
\hline Evening (fixed) & 5.6 \\
\hline Night (fixed) & 0.9 \\
\hline Rotation & 73.7 \\
\hline
\end{tabular}

$S D=$ standard deviation

between items within scales and between-scale correlations as well as scaling success. The scaling success rate for the psychological job demands, social support, physical exertion, physical

\begin{tabular}{|c|c|c|c|}
\hline Scale & Mean (SD) scores & Min-Max scores & Min-Max attainable score \\
\hline Decision latitude $(n=9)$ & $64.2(7.3)$ & $44-80$ & $24-96$ \\
\hline Skill discretion $(n=6)$ & $33.7(5.0)$ & $16-48$ & $12-48$ \\
\hline Decision authority $(n=3)$ & $30.5(4.3)$ & $20-40$ & $12-48$ \\
\hline Psychological job demands $(n=9)$ & $12.3(2.9)$ & 5-19 & $-6-21$ \\
\hline Social support $(n=8)$ & $21.7(4.1)$ & $10-30$ & $8-48$ \\
\hline Supervisor support $(n=4)$ & $10.6(2.9)$ & $4-16$ & $4-32$ \\
\hline Coworker support $(n=4)$ & $11.2(2.0)$ & $4-15$ & $4-16$ \\
\hline Physical exertion $(n=3)$ & $9.8(1.6)$ & $6-12$ & $3-12$ \\
\hline Physical isometric loads $(n=2)$ & $6.3(1.3)$ & $4-8$ & $2-8$ \\
\hline Total physical hazards $(n=8)$ & $9.0(4.2)$ & $0-16$ & $0-16$ \\
\hline Hazardous conditions $(n=5)$ & $5.3(2.7)$ & $0-10$ & $0-10$ \\
\hline Toxic exposures $(n=3)$ & $3.7(1.7)$ & $0-6$ & $0-6$ \\
\hline
\end{tabular}

$S D=$ standard deviation; $n=$ number of items. 


\begin{tabular}{lc}
\hline $\begin{array}{l}\text { Table } 3 \text { Internal consistency of the Persian version of the job content } \\
\text { questionnaire scales }(\boldsymbol{n}=\mathbf{1 0 7})\end{array}$ \\
\hline Scale & Cronbach alpha coefficient \\
Decision latitude $(\mathrm{n}=9)$ & 0.54 \\
Skill discretion $(\mathrm{n}=6)$ & 0.59 \\
Decision authority $(\mathrm{n}=3)$ & 0.48 \\
Psychological job demands $(\mathrm{n}=9)$ & 0.58 \\
Social support $(\mathrm{n}=8)$ & 0.85 \\
Supervisor support $(\mathrm{n}=4)$ & 0.90 \\
Coworker support $(\mathrm{n}=4)$ & 0.79 \\
Physical exertion $(\mathrm{n}=3)$ & 0.64 \\
Physical isometric loads $(\mathrm{n}=2)$ & 0.81 \\
Total physical hazards $(\mathrm{n}=8)$ & 0.85 \\
Hazardous conditions $(\mathrm{n}=5)$ & 0.78 \\
Toxic exposures $(\mathrm{n}=3)$ & 0.70 \\
\hline
\end{tabular}

$n=$ number of items.

isometric loads and total physical hazards scales were all above $75 \%$, indicating high convergent validity, whereas the rate for the decision latitude scale was below $75 \%$.

Statistical analysis used for assessing disconvergent validity revealed a correlation only between physical exertion and physical isometric loads scales $(r=0.66)$, which was justifiable because both scales were related to physical activity and measured nearly similar dimensions of the job. For the other scales, a negative or very weak positive correlation was found, physical isometric loads scales together with 2 items of physical exertion scale (i.e. q24 and q25) and 2 items of psychological job demands (i.e. q28 and q32) formed the second factor (loading range: $0.23-0.80$ ), reflecting physical loads and hazards exposure.

Factor 3 (F3): items of the skill discretion and coworker support subscales together with 4 items of psychological job demands scale (i.e. q19, q20, q27 and q29) and one item of physical exertion scale (i.e. q21) formed the third factor (loading range: $0.23-0.74$ ), reflecting psychological job demands.

As shown in Table 5, item q10 (lots of say) was not associated with any factor.

showing acceptable disconvergent validity of the P-JCQ.

\section{Construct validity}

Exploratory factor analysis of 39 items produced 3 factors (Table 5).

Factor 1 (F1): items of the supervisor support subscale, 3 items of decision latitude scale (i.e. $\mathrm{q} 4, \mathrm{q} 6$ and $\mathrm{q} 8$ ) and 3 items of psychological job demands scale (i.e. q22, q23 and q26) formed the first factor (loading range: $0.42-0.79$ ) reflecting social support.

Factor 2 (F2): items of the hazardous conditions, toxic exposures and

\section{Discussion}

With the development of industrialization in the Islamic Republic of Iran job stress has grown as an occupational health issue and is attracting increasing concern. In this situation, conducting systematic studies on job stress using valid, applicable instruments for measuring job stress dimensions are essential. Since Karasek published the results of his studies $[2,9,11]$, the job demands-control-support model has been an extremely important model in

\begin{tabular}{|c|c|c|c|}
\hline Scale & Convergent validity (range of correlation) & Scaling success ${ }^{\mathrm{a}}$ & Scaling success rate (\%) \\
\hline Decision latitude $(n=9)$ & $0.13-0.64$ & $4 / 9$ & 44.4 \\
\hline Skill discretion $(n=6)$ & $0.25-0.68$ & $5 / 6$ & 83.3 \\
\hline Decision authority $(n=3)$ & $0.32-0.66$ & $2 / 3$ & 66.7 \\
\hline Psychological job demands $(n=9)$ & $0.27-0.61$ & $8 / 9$ & 88.9 \\
\hline Social support $(n=8)$ & $0.40-0.84$ & $7 / 8$ & 87.5 \\
\hline Supervisor support $(n=4)$ & $0.78-0.92$ & $4 / 4$ & 100.0 \\
\hline Coworker support $(n=4)$ & $0.59-0.83$ & $4 / 4$ & 100.0 \\
\hline Physical exertion $(n=3)$ & $0.62-0.85$ & $3 / 3$ & 100.0 \\
\hline Physical isometric loads ( $n=2)$ & $0.92-0.93$ & $2 / 2$ & 100.0 \\
\hline Total physical hazards $(n=8)$ & $0.45-0.82$ & $8 / 8$ & 100.0 \\
\hline Hazardous conditions $(n=5)$ & $0.64-0.82$ & $5 / 5$ & 100.0 \\
\hline Toxic exposures $(n=3)$ & $0.46-0.90$ & $3 / 3$ & 100.0 \\
\hline
\end{tabular}

${ }^{a}$ Number of correlations between items and hypothesized scale corrected for overlap $>0.4 /$ total number of convergent validity tests. $n=$ number of items. 


\begin{tabular}{|c|c|c|c|}
\hline Scale/item & F1 & F2 & F3 \\
\hline \multicolumn{4}{|l|}{ Decision latitude } \\
\hline Learn new things & - & - & 0.51 \\
\hline Repetitive work & 0.47 & - & - \\
\hline Requires creativity & - & - & 0.23 \\
\hline High skill level & - & - & 0.49 \\
\hline Variety & - & - & 0.42 \\
\hline Develop own abilities & - & - & 0.43 \\
\hline Allow own decision & 0.46 & - & - \\
\hline Little freedom of decision & 0.47 & - & - \\
\hline Lots of say & - & - & - \\
\hline \multicolumn{4}{|l|}{ Psychological job demands } \\
\hline Work fast & - & - & 0.60 \\
\hline Work hard & - & - & 0.74 \\
\hline Intensive concentration & - & & 0.44 \\
\hline Interrupted tasks & - & 0.23 & - \\
\hline Hectic job & - & & 0.43 \\
\hline Waiting for others & - & 0.44 & - \\
\hline No excessive work & 0.53 & - & - \\
\hline Enough time & 0.42 & - & - \\
\hline Conflicting demands & 0.48 & - & - \\
\hline \multicolumn{4}{|l|}{ Social support } \\
\hline Supervisor is concerned & 0.72 & - & - \\
\hline Supervisor pays attention & 0.71 & - & - \\
\hline Helpful supervisor & 0.79 & - & - \\
\hline Supervisor good organizer & 0.62 & - & - \\
\hline Coworkers competent & - & - & 0.42 \\
\hline Coworkers interested in me & - & - & 0.69 \\
\hline Friendly coworkers & - & - & 0.68 \\
\hline Coworkers helpful & - & - & 0.63 \\
\hline \multicolumn{4}{|l|}{ Physical exertion } \\
\hline Physical effort & - & - & 0.59 \\
\hline Moving/lifting heavy loads & - & 0.57 & - \\
\hline Rapid/continuous physical activity & - & 0.46 & - \\
\hline \multicolumn{4}{|l|}{ Physical isometric loads } \\
\hline Awkward working postures & - & 0.44 & - \\
\hline Head/arm awkward working postures & - & 0.45 & - \\
\hline \multicolumn{4}{|l|}{ Total physical hazards } \\
\hline Exposure to things stored dangerously & - & 0.71 & - \\
\hline Exposure to dirty areas & - & 0.62 & - \\
\hline $\begin{array}{l}\text { Exposure to dangerous tools, } \\
\text { equipment }\end{array}$ & - & 0.73 & - \\
\hline Exposure to fire, burn or shock & - & 0.63 & - \\
\hline Exposure to dangerous work method & - & 0.64 & - \\
\hline Exposure to dangerous chemicals & - & 0.79 & - \\
\hline Exposure to air pollution & - & 0.80 & - \\
\hline Catching diseases & - & 0.44 & - \\
\hline
\end{tabular}

the research into work environment, stress and health in recent decades [1]. Occupational health psychological studies mostly using the JCQ, revealed that a poor psychosocial environment and job stress led to a wide range of health problems [1-8].

In the linguistic validation stage of our study, the main objective was to obtain a conceptual equivalence between the original and translated version of the JCQ, allowing, among other things, a pooling and comparison of data from local and international studies. The translation of the JCQ into Persian was carried out within the framework of internationally accepted methodologies. We found that there was no major ambiguity in the translated version and, with few exceptions, the participants understood the questions. Suggestions from the JCQ Center also contributed to the removal of problematic translations and the preparation of an acceptable, equivalent Persian translation of the questionnaire. The translated JCQ therefore went through successful cognitive debriefing.

In psychometric evaluation stage of the study among hospital nurses, the pattern of scores was similar to studies in other Asian countries. The mean score of decision latitude (64.2) was close to that of the Asian countries of Japan (64.5) [14], South Korea (60.6) [10] and China (63.8) [1]. The mean score of the psychological job demands scale consisting of 9 items were 12.3. Since in other studies this scale consisted of 5 items, the results of our study were not comparable with those of other studies. The mean score of social support in the present study (21.7) was comparable to that of Japan (23.7) [14], Korea (23.3) [10] and China (22.3) [1]. The mean scores of the physical exertion, physical isometric loads and total physical hazards scales were 9.8, 6.3 and 9.0 respectively. As these scales were not investigated in other studies, we could not compare our results with others. 
For the nurses in this study, internal consistency was low for skill discretion (Cronbach alpha $=0.59)$ and decision authority $(\alpha=0.48)$. Li et al. and Eum et al. reported a low internal consistency for skill discretion among health care workers $[1,10]$. In our study internal consistency for decision latitude scale and its subscales was lower than that of other Asian countries, but totally the result of our study was in line with those studies, for they reported relatively low internal consistency for this scale. Psychological job demands had a low alpha $(\alpha=0.58)$. According to other studies, the Cronbach alpha coefficient for this scale ranged from 0.5 to 0.7 . Our result for this scale was, therefore, in agreement with previous studies $[1,10,14]$. Consistent with $\mathrm{Li}$ et al. [1] and Kawakami et al. [14], internal consistency for the social support scale was highly acceptable $(\alpha=0.85)$. Eum et al. reported lower Cronbach alpha coefficient for social support ( $\alpha=$ 0.71) among South Korean health care workers [10]. Internal consistency for the physical exertion scale was satisfactory $(\alpha=0.64)$ and highly acceptable for physical isometric loads $(\alpha=0.81)$ and total physical hazards $(\alpha=0.85)$. Since these scales were not investigated in the previous studies, the results could not be compared to any other populations or occupational groups.

The results of convergent validity assessment of the P-JCQ showed that except for decision latitude scale and one of its subscale (decision authority) in which scaling success rate was less than $75 \%$, in other scales, the scaling success rate was higher than $75 \%$ and in 7 scales was $100 \%$. This indicated high convergent validity of the P-JCQ. In Li et al.'s study, 2 of 6 items of the skill discretion scale and 3 of 5 items of the psychological job demands scale had correlation coefficients less than 0.4 , indicating scaling success rate to be less than $75 \%$ [1]. Our results also showed that the disconvergent validity was acceptable. This is in agreement with $\mathrm{Li}$ et al. [1].

Exploratory factor analysis showed that among the study nurses the first factor was associated with items of the supervisor support subscale, decision latitude scale and psychological job demands scale, reflecting social support, whereas in South Korean [10] and Chinese [1] health care workers it was items of the social support scale that formed this factor. The results of factor analysis also revealed that the second factor was clearly associated with the items of physical exertion, physical isometric loads, total physical hazards and psychological job demands scales. The results also indicated that the third factor was associated with items of skill discretion and coworker support subscales as well as the psychological job demands scale reflecting psychological job demands. Whereas the psychological job demands scale consisted of 5 items in Li et al. [1] and Eum et al. [10], in the present study, there were 9 items in this scale, which were loaded onto 3 factors ( 3 on the first factor, 2 on the second factor and 4 on the third factor). Based on the results of factor analysis, it could be inferred that only in the psychological job demands scale, the related items were not associated to 1 certain factor and loaded on more than 1 factor. Items of other scales were found to be associated to the related factor.

The major limitation of this study was that the subjects were from a certain occupational group (i.e. hospital nurses) and the study population did not include a variety of occupations. The P-JCQ should be applied to workers in other occupations in future studies.

On the whole, these findings suggest that the P-JCQ has satisfactory linguistic validity and psychometric properties and can be applied for assessing psychosocial job stress among Iranian workers, provided the recommended factor pattern is used. Further research is needed to reach conclusive results for the psychological job demands scale of the P-JCQ.

\section{Acknowledgements}

The authors wish to thank Bongkyoo Choi and Sandra Gibson from the JCQ Center for their suggestions in development of the Persian version of the JCQ.

The authors also wish to thank Dr Shokrpour for her assistance in forward translation and Mrs. Sedigh for her hard work in backward translation.

Funding through Shiraz University of Medical Sciences, Contract No. 852941 , supported this investigation.

\section{References}

1. Li J et al. Psychometric evaluation of the Chinese (mainland) version of Job Content Questionnaire: a study in university hospitals. Industrial Health, 2004, 42:260-267.

2. Theorell T, Karasek RA. Current issues relating to psychosocial job strain and cardiovascular disease research. Journal of Occupational Health Psychology, 1996, 1:9-26.

3. Levi L et al. Stressors at the workplace: theoretical models. Occupational Medicine, 2000, 15:69-106.

4. Cole DC et al. Work correlates of back problems and activity restriction due to musculoskeletal disorders in the Canadian national population health survey (NPHS) 1994-5 data. Occupational and Environmental Medicine, 2001, 58:728-734.

5. Ariëns GA et al. High physical and psychosocial load at work and sickness absence due to neck pain. Scandinavian Journal of Work, Environment and Health, 2002, 28:222-231.

6. Schnall PL, Landsbergis PA, Baker D. Job strain and cardiovascular disease. Annual Review of Public Health, 1994, 15:381-411.

7. Kristensen TS. Job stress and cardiovascular disease: a theoretic critical review. Journal of Occupational Health Psychology, $1996,1: 246-260$ 
8. Cheng Y, Luh WM, Guo YL. Reliability and validity of the Chinese version of the Job Content Questionnaire in Taiwanese workers. International Journal of Behavioral Medicine, 2003, 10:15-30

9. Karasek RA et al. The Job Content Questionnaire (JCQ): an instrument for internationally comparative assessments of psychosocial job characteristics. Journal of Occupational Health Psychology, 1998, 3:322-355.

10. Eum KD et al. Psychometric properties of the Korean version of the job content questionnaire: data from health care workers. International Archives of Occupational and Environmental Health, 2007, 80:497-504.

11. Karasek RA. Job Content Questionnaire and user's guide. Lowell, Massachusetts, Department of Work Environment, University of Massachusetts, 1985.
12. Choobineh AR, Ghaem H, Ahmadi Nejad P. Development of the Persian version of the Job Content Questionnaire: assessment of job stress among hospital nurses of Shiraz city. In: Proceedings of the 1st International Conference on Ergonomics, 7-8 May 2008, Tehran, Islamic Republic of Iran. Tehran, Iranian Ergonomics Society, 2008:62-69.

13. Cronbach LJ. Coefficient $\alpha$ and the internal structure of tests. Psychometrika, 1951, 16:297-334.

14. Kawakami $\mathrm{N}$ et al. Assessment of job stress dimensions based on the job demands- control model of employees of telecommunication and electric power companies in Japan: reliability and validity of the Japanese version of the Job Content Questionnaire. International Journal of Behavioral Medicine, 1995, 2:358-375.

\section{World Conference of Science Journalists, Doha, Qatar 27-29 June 2011}

The organizers have taken the decision to relocate this conference from Cairo to Doha, Qatar, on the invitation of the Qatar Foundation. The conference dates remain the same. The programme covers a wide variety of topics, incuding sessions on topics relevant to the health issues in our Region such as:

- Reporting on Climate Change and Biodiversity,

- Teaching Science Journalism;

- Bioethics in the Media;

- Clinical Trials in Developing Countries: Undue Exploitation or Mutual Benefit?

- Disaster Reporting: Lessons from Japan;

- Can You Hear Me Now? Writing for a Non-English Audience;

- How to Read Medical Studies (and Avoid Pitfalls).

Further information and complete details of the programme can be found on the conference website at: http://www.wcsj2011.org/ 